BMJ Paediatrics Open

\section{Congenital heart disease and the prevalence of underweight and obesity from age 1 to 15 years: data on a nationwide sample of children}

Sara Schwartz, ${ }^{1}$ Morten Olsen, ${ }^{1}$ Jessica G Woo, ${ }^{2,3,4}$ Nicolas Madsen ${ }^{2,4}$
To cite: Schwartz S, Olsen M, Woo JG, et al. Congenital heart disease and the prevalence of underweight and obesity from age 1 to 15 years: data on a nationwide sample of children. BMJ Paediatrics Open 2017;1:e000127. doi:10.1136/ bmjpo-2017-000127

- Additional material is published online only. To view please visit the journal online (http://dx.doi.org/10.1136/ bmjpo-2017-000127).

Received 30 May 2017 Revised 27 August 2017 Accepted 29 August 2017

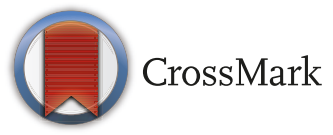

${ }^{1}$ Department of Clinical Epidemiology, Aarhus University Hospital, Denmark, Europe ${ }^{2}$ Heart Institute, Cincinnati Children's Hospital Medical Center, Cincinnati, Ohio, USA ${ }^{3}$ Division of Biostatistics and Epidemiology, Cincinnati Children's Hospital Medical Center, Cincinnati, Ohio, USA ${ }^{4}$ Department of Pediatrics, University of Cincinnati College of Medicine, Cincinnati, Ohio, USA

Correspondence to Sara Schwartz; sarabendtsen@ hotmail.com

\section{ABSTRACT}

Objective We examined the prevalence of underweight and obesity in children with congenital heart disease (CHD) compared with the general population.

Methods Using the Danish National Patient Registry, we identified individuals born and diagnosed with CHD in Denmark during 1996-2012 who were alive at 1 year of age. $A$ unique personal identifier enabled identification of CHD subjects, as well as birth year and sex-matched (1:10) general population controls. The Children's Database has recorded height and weight measured by clinical providers at preventive health checks offered to all children in Denmark. Data recording were made mandatory in 2011 Obesity was defined as body mass index (BMI) above the 95thpercentile and underweight as BMI below the fifth percentile for age and sex. We determined the prevalence of underweight and obesity at study subjects' first height and weight recording. For those underweight at age 1 year, prevalence of underweight and obesity at later recordings was assessed.

Results We identified 9194 children with CHD of which $2679(29 \%)$ had at least one recording of height and weight. The control cohort demonstrated a similar portion of anthropometric data: 30047 (31\%) of 96585 controls. The prevalence of underweight and obesity at CHD study subjects' first height and weight recording was 9.7\% (95\% $\mathrm{Cl} 8.7$ to 11$)$ and $4.1 \%(95 \% \mathrm{Cl} 3.4$ to 4.9$)$, respectively. Among individuals with $\mathrm{CHD}$ who were underweight at age 1 year $(n=78), 51$ (65\%) had additional BMl recordings between ages 2 and 5 years with a subsequently diminished prevalence of underweight of $27 \%$ (95\% Cl 20 to 35) and none were obese.

Conclusion The CHD population had an increased prevalence of underweight compared with the general population. Data indicated potential for BMI normalisation among those initially underweight at age 1 year. The prevalence of obesity in children with CHD was comparable with that of the general population.

\section{INTRODUCTION}

Children with congenital heart disease (CHD) face unique metabolic challenges that may increase the risk of both insufficient and excessive weight gain, both of which are associated with morbidity and mortality. ${ }^{1-3}$
What is already known on this topic?

Children with congenital heart disease (CHD) commonly have unique metabolic challenges such as failure to thrive or exercise intolerance.

- Studies on body mass index in this population have primarily been based on data collected during hospital or outpatient clinic visits.

- Reported obesity prevalence estimates for individuals with CHD have been comparable to normative data.

\section{What this study hopes to add?}

We report estimates of body mass index (BMI) in the congenital heart disease (CHD) population based on data from nationwide preventive health checks offered to all children and adolescents in Denmark.

- The prevalence of obesity among children with CHD was comparable to the general population, while the prevalence of underweight was increased.

Among those who were underweight at 1 year of age, with additional BMI recordings between ages 2 and 5 years, the prevalence of underweight decreased substantially.

Decreased energy intake, malabsorption and increased basal energy requirements may all lead to compromised growth and underweight in children with CHD. ${ }^{4}$ Studies have reported associations of impaired haemodynamic status with impaired growth and with lower body mass index (BMI) ${ }^{56}$ On the other hand, as the incidence of overweight and obesity increases in the general population, ${ }^{7}$ a similar and potentially more pronounced trend might be expected of the CHD population. This may be exacerbated in the CHD population because of potential exercise intolerance and recommendations of activity restriction. Furthermore, children with CHD 
are often born premature, which has been linked to increased risk of overweight/obesity. ${ }^{8}$

Most existing studies reporting on the BMI of individuals with CHD have been based on data obtained at one or more hospital clinics ${ }^{9-15}$ using healthy individuals referred to the clinics ${ }^{91015}$ or standard population BMI normative data for comparison. ${ }^{11-14}$ Some have included a few specific CHD diagnoses, ${ }^{13} 14$ while others a broad range of CHD subtypes. ${ }^{9-1215}$ To our knowledge, the only previous study that was not clinic-based or hospital-based, and the only study to include controls from the general population, is a cross-sectional city-wide study conducted in Taiwan in 2012. ${ }^{16}$

The aim of the present study was to examine the prevalence of abnormal BMI (underweight or obesity) in children aged 1-15 years with CHD in comparison to the general population based on data from nationwide preventive health checks offered to all children and adolescents in Denmark. We paid particular attention to those underweight at 1 year age who had subsequent BMI data available at older ages.

\section{METHODS}

\section{Setting}

This prevalence study was conducted in Denmark, with a current population of approximately 5.7 million individuals. The Danish National Health Service provides tax-supported healthcare with free access to hospital-based and primary medical care, including care for CHD.

\section{Data linkage}

Since 1968, a unique 10-digit civil personal registration (CPR) number has been assigned to all residents of Denmark by the Central Office of Civil Registration. ${ }^{17}$ The CPR numbers are used in all Danish registries, permitting unambiguous individual-level linkage of data from all sources used in this study. This provided us with virtually complete follow-up for death and emigration. The Civil Registration System also made it possible to identify a comparison population from the general population. ${ }^{18}$

\section{Study population}

Using the Danish National Patient Registry (DNPR), we identified all individuals born and diagnosed with CHD in Denmark during 1996-2012. Specific International Classification of Diseases (ICD) codes, previously described, ${ }^{19}$ were used to identify CHD subjects. The DNPR contains information on all hospital admissions in Denmark; it includes patient civil registration numbers, dates of admission and discharge, surgical procedures, and up to 20 discharge diagnoses coded by physicians according to the 10th edition of the ICD since 1994 (eighth edition used prior).

As previously described, ${ }^{20}$ severity of CHD was categorised as mild (biventricular without any history of surgery or intervention), moderate (biventricular with a history of surgery or intervention), severe (complex biventricular physiology), univentricular (history of single ventricle diagnoses or palliative surgery including Norwood, Glenn and Fontan) and unclassified. For each CHD subject, we identified 10 population comparison individuals from the general population using the Civil Registration System, matched by sex and birth year. ${ }^{18}$ Study subjects who died or emigrated before the age of 1 year were excluded. Study subjects with no recorded data on both height and weight were also excluded (online supplementary figure 1).

\section{Body mass index}

The Children's Database ${ }^{21}$ records height and weight as measured by medical doctors and nurses at annual preventive health checks offered to all Danish children. The database was established in 2009 and became compulsory in 2011. Previously existing electronic data recordings dating back to the 1990s were included in the database but with markedly decreased completeness. Using the CPR number, data from the Children's Database were linked to the study population. Outliers were defined as follows: height above $220 \mathrm{~cm}$ or below $55 \mathrm{~cm}$, weight above $125 \mathrm{~kg}$ or below $5 \mathrm{~kg}$ and BMI above 50 or below 10 .

BMI was calculated as weight (in kilograms) divided by height (in metre squared). Obesity and underweight were calculated using our general population comparison cohort as the reference, with obesity defined as BMI above the 95th percentile of our population by sex and age in years and underweight defined as BMI below the fifth percentile. In addition, for use in sensitivity analyses, we also defined obesity and underweight using international sex-specific and age-specific BMI cut-off values. ${ }^{22} 23$

\section{Covariates}

Using the Danish Medical Birth Registry, we obtained data on gestational age at birth. ${ }^{24}$ In addition, we also used the DNPR to identify diagnoses for extracardiac defects (ECD) including chromosomal abnormalities in accordance with a guideline from the European Surveillance of Congenital Anomalies ${ }^{25}$ as previously described. ${ }^{20}$

\section{Data analysis}

We performed descriptive analyses for the CHD and comparison populations before and after exclusion of individuals without recorded BMI, to evaluate generalisability of the overall results. Based on individuals' first time BMI recordings, we determined the median BMI, prevalence of obesity and underweight according to categories of age in years and sex, presented graphically with corresponding 95\% CIs. We used Cox proportional hazards regression to estimate the relative risk of having a recording of obesity or underweight. We computed HRs of obesity or underweight recordings in CHD subjects compared with birth year and sex-matched general population subjects. Subjects entered the study at date 
Table 1 Characteristics of individuals with $\mathrm{CHD}$ and sex-matched and age-matched controls from the general population including separation by those with available height and weight (BMI) in the Children's Database

\begin{tabular}{|c|c|c|c|c|}
\hline & \multicolumn{2}{|c|}{ CHD subjects } & \multicolumn{2}{|c|}{ General population subjects } \\
\hline & BMI data & All & BMI data & All \\
\hline & n (\%) & n (\%) & n (\%) & n (\%) \\
\hline All & $2679(100)$ & $9.194(100)$ & $30047(100)$ & $96.585(100)$ \\
\hline Male & $1336(50)$ & $4.612(50)$ & $14999(50)$ & $4.612(50)$ \\
\hline \multicolumn{5}{|l|}{ Birth year } \\
\hline $1996-1998$ & $564(21)$ & $1.793(20)$ & $6547(22)$ & $19.233(20)$ \\
\hline 1999-2001 & $521(19)$ & $1.729(19)$ & $6399(21)$ & $18.503(19)$ \\
\hline 2002-2004 & $717(27)$ & 1.717 (19) & $7732(26)$ & $18.035(19)$ \\
\hline 2005-2007 & $514(19)$ & $1.842(20)$ & $6186(21)$ & $19.156(20)$ \\
\hline 2008-2012 & $363(14)$ & $2.113(23)$ & $3183(11)$ & $21.658(22)$ \\
\hline Extracardiac defects & $596(22)$ & $2.314(25)$ & $1482(5)$ & $4.859(5)$ \\
\hline Preterm birth & $470(18)$ & $1.603(17)$ & $1859(6)$ & $5.604(6)$ \\
\hline \multicolumn{5}{|l|}{ Severity } \\
\hline Mild (biventricular, no surgery) & $1301(49)$ & $45.528(47)$ & - & - \\
\hline Moderate (biventricular, surgery) & $320(12)$ & $10.858(11)$ & - & - \\
\hline Severe & $669(25)$ & $24.730(26)$ & - & - \\
\hline Univentricular & $108(4)$ & $5.374(6)$ & - & - \\
\hline Not classified & $281(10)$ & $10.095(10)$ & - & - \\
\hline \multicolumn{5}{|l|}{ Major CHD diagnoses } \\
\hline ASD & $593(22)$ & $2.040(22)$ & - & - \\
\hline $\mathrm{CoA}$ & $97(4)$ & $342(4)$ & - & - \\
\hline PDA & $210(8)$ & $745(8)$ & - & - \\
\hline TGA & $80(3)$ & $279(3)$ & - & - \\
\hline TOF & $90(3)$ & $273(3)$ & - & - \\
\hline VSD & $657(25)$ & $2.229(24)$ & - & - \\
\hline Other & $952(36)$ & $3.286(36)$ & - & - \\
\hline \multicolumn{5}{|l|}{ BMI measurements, $n$} \\
\hline 1 & $1596(60)$ & - & $17846(59)$ & - \\
\hline $2-4$ & $854(32)$ & - & 9618 (32) & - \\
\hline $5-9$ & $223(8)$ & - & $2534(8)$ & - \\
\hline$>10$ & $6(0)$ & - & $49(0)$ & - \\
\hline \multicolumn{5}{|l|}{ Year of first BMI measurements } \\
\hline 1996-1999 & $70(3)$ & - & $684(2)$ & - \\
\hline 2000-2004 & $224(8)$ & - & $2503(8)$ & - \\
\hline 2005-2009 & $615(23)$ & - & $7252(24)$ & - \\
\hline 2010-2012 & $1770(66)$ & - & $19608(65)$ & - \\
\hline \multicolumn{5}{|l|}{ Age at first BMI, years } \\
\hline $1-4$ & $941(35)$ & - & $9186(31)$ & - \\
\hline $5-6$ & $587(22)$ & - & $8270(28)$ & - \\
\hline $7-9$ & 497 (19) & - & $4912(16)$ & - \\
\hline $10-15$ & $654(24)$ & - & $7679(26)$ & - \\
\hline
\end{tabular}

ASD, atrial septal defect; BMI, body mass index; CHD, congenital heart disease; CoA, coarctation of the aorta; PDA, persistent ductus arteriosus; TGA, transposition of the great arteries; TOF, Tetralogy of Fallot; VSD, ventricular septal defect. 

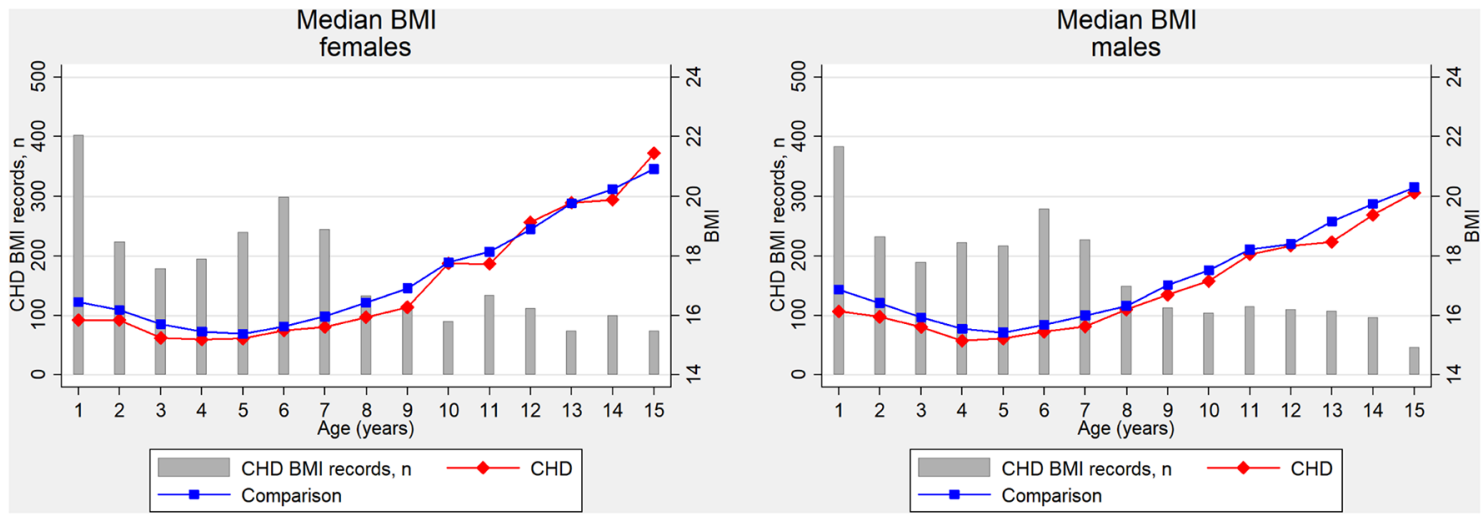

Figure 1 Median body mass index (BMI) of female and male individuals with $(n=2679)$ and without $(n=30047)$ congenital heart disease (CHD). Individuals may appear in more than one age group.

of CHD diagnosis (index date for matched comparison individuals) and were followed until emigration, death, first underweight or obesity recording, or end of study January 1 2013, whichever came first. The assumption of proportional hazards was graphically assessed and found to be valid. We repeated the analyses in subgroups of patients with CHD according to CHD severity, presence of ECDs and presence of preterm birth. We also performed a sensitivity analyses with inclusion of subjects identified to be outliers. Analyses were performed with Stata V.14 (StataCorp).

The study was approved by the Danish Data Protection Agency. The role of this agency is to protect the privacy of individuals whose data are recorded in Danish registries. The informed consent of participants was not required for this study.

\section{RESULTS}

We identified 9194 children with CHD alive at more than 1year of age; of whom 2679 (29\%) had at least one recording of height and weight in the Children's Database. A total of 30047 (31\% of 96585 total general population controls) of the matched comparison individuals had at least one BMI recording. Among the CHD subjects, 1336 (50\%) were men, $22 \%$ had ECDs including chromosomal anomalies and $18 \%$ were born preterm. Among the matched comparison individuals, 14999 (50\%) were men, $5 \%$ had ECDs including chromosomal anomalies and 6\% were born preterm (table 1). The most prevalent CHD diagnoses were ventricular septal defects (VSD) (25\%), atrial septal defect (22\%) and persistent ductus arteriosus $(8 \%)$.

Most study subjects had only one BMI recording (1301 (60\%) CHD subjects and 17846 (59\%) comparison individuals). The majority of study subjects with more than one BMI recording had two to four recordings. BMI recordings were made during the years 1996-2012, with the majority after 2009 (65\%) (table 1). For the CHD population, as well as for the general population, the descriptive characteristics of those eligible for BMI recordings were almost identical to those within the population who obtained these recordings (table 1 ).

Median BMI was slightly lower for individuals with CHD relative to the general population subjects for almost all ages from 1 to 15 for both boys and girls (figure 1). The overall prevalence of underweight at first recording in the Children's Database was $4.9 \%$ (95\% CI 4.7 to 5.1) for the general population subjects and $9.8 \%$ (95\% CI 8.7 to 11 ) for the CHD population (figure 2). The corresponding estimate for CHD subjects born at term without ECDs was
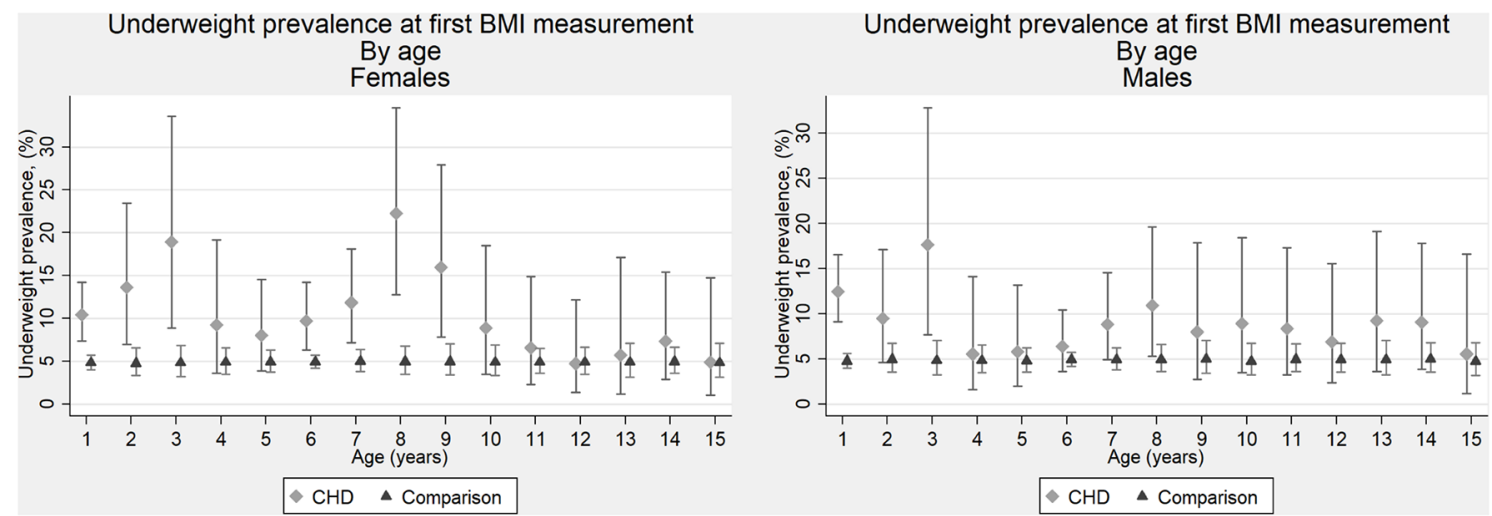

Figure 2 Prevalence of underweight (body mass index (BMI) <fifth percentile) in female and male individuals with and without congenital heart disease (CHD) at their first recording of height and weight. 


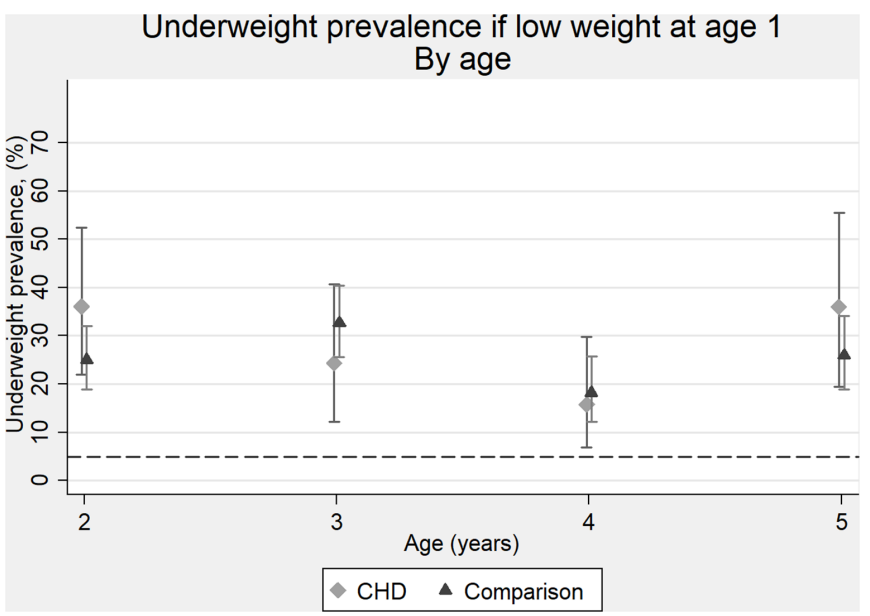

Figure 3 Prevalence of underweight (body mass index $<$ fifth percentile) at ages 2-5 among individuals with and without congenital heart disease (CHD) who were underweight at age 1 year.

$7.9 \%$ (95\% CI 6.7 to 9.3 ) (online supplementary figure 2). The prevalence of underweight was consistently elevated for both boys and girls with CHD from 1 to 15 years of age, particularly under age 5 in both sexes, although

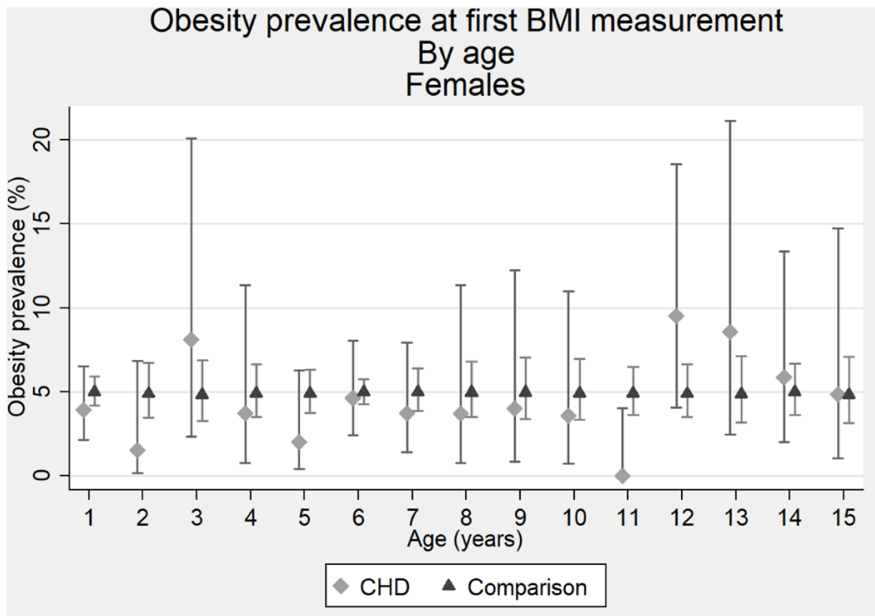

Obesity prevalence at first BMI measurement By age. International obesity cut off. Females

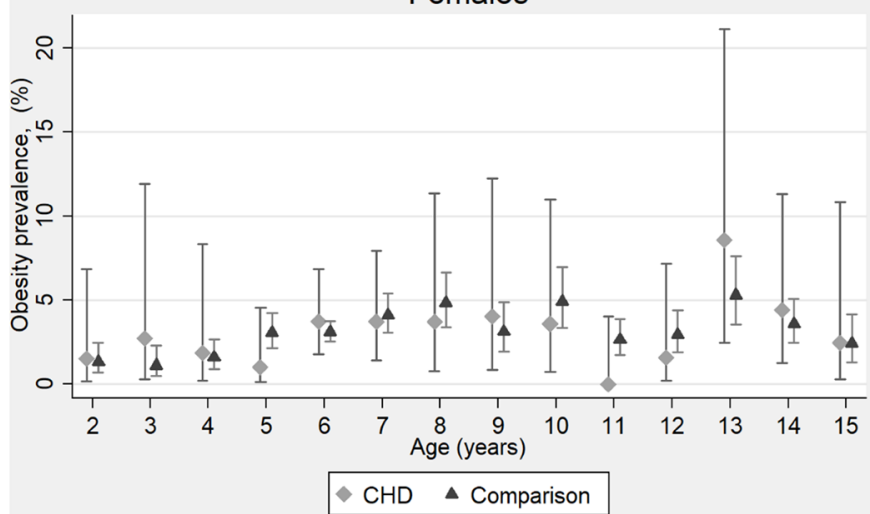

not statistically significantly for all age groups (figure 2). Among individuals with CHD who were underweight at age 1 year $(n=78), 51(65 \%)$ had additional BMI measurements between the ages of 2 and 5 years. The prevalence of underweight at these later ages reduced substantially to $27 \%$ (95\% CI 20 to 35) in both the CHD and population control groups, and none became obese (figure 3 ).

The overall prevalence of obesity at first recording in the Children's Database was $4.9 \%$ (95\% CI 3.7 to 5.7$)$ in general population subjects and $4.1 \%$ (95\% CI 3.4 to 4.9 ) in the overall CHD population and $4.6 \%$ (95\% CI 3.7 to 5.7) for those born at term without ECDs (online supplementary figure 3). The prevalence of obesity among CHD subjects displayed some variation according to age, with estimates not statistically significantly different between subjects with CHD compared with general population individuals of same age and sex (figure 4). Using the international age-specific and sex-specific BMI cut-off values for obesity, the overall prevalence of obesity dropped to $2.3 \%$ (95\% CI 1.8 to 2.9 ) in the CHD subject and to $2.5 \%$ (95\% CI 2.3 to 2.7$)$ in the general population (figure 4 ).

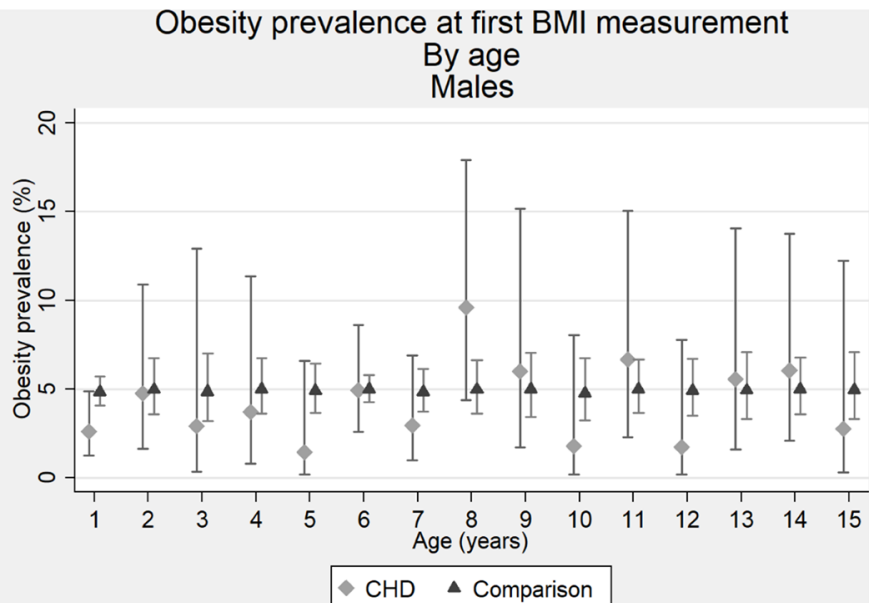

Obesity prevalence at first BMI measurement By age. International obesity cut off. Males

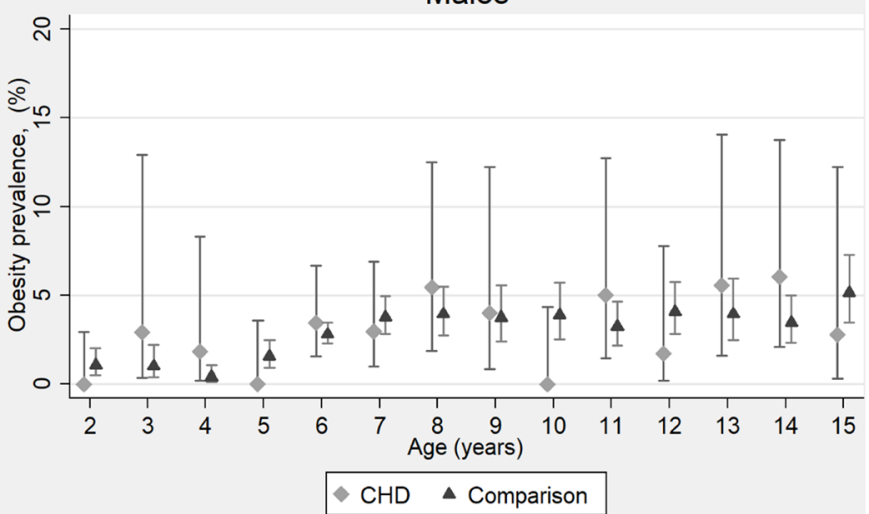

Figure 4 Prevalence of obesity in female and male individuals with and without congenital heart disease (CHD) at their first recording of height and weight. Top panels are based on Danish general population obesity cut-off values (body mass index (BMI) >95th percentile). Bottom row panels are based on published international age-specific and sex-specific cut-off values equivalent to $\mathrm{BMI}>30$. 
Table 2 HRs of underweight or obesity for individuals with congenital heart disease compared with the general population

\begin{tabular}{lll}
\hline & \multicolumn{2}{c}{ HR (95\% Cl) } \\
\cline { 2 - 3 } & Underweight & Obesity \\
\hline All & $2.0(1.8$ to 2.3$)$ & $0.8(0.7$ to 1.0$)$ \\
\hline Male & $1.9(1.5$ to 2.3$)$ & $0.8(0.6$ to 1.1$)$ \\
\hline Female & $2.2(1.8$ to 2.7$)$ & $0.9(0.6$ to 1.2$)$ \\
\hline Severity & & \\
$\quad \begin{array}{l}\text { Mild (biventricular, no } \\
\text { surgery) }\end{array}$ & $2.0(1.6$ to 2.5$)$ & $0.9(0.6$ to 1.2$)$ \\
\hline $\begin{array}{l}\text { Moderate (biventricular, } \\
\text { surgery) }\end{array}$ & $1.7(1.1$ to 2.6$)$ & $0.7(0.4$ to 1.4$)$ \\
\hline $\begin{array}{l}\text { Severe } \\
\text { Univentricular }\end{array}$ & $2.5(1.9$ to 3.3$)$ & $0.7(0.4$ to 1.1$)$ \\
\hline \begin{tabular}{l} 
Unclassified \\
\multicolumn{1}{l}{ Born preterm }
\end{tabular} & $0.3(1.9$ to 5.7$)$ & $0.2(0.03$ to 1.5$)$ \\
\hline With extracardiac defects & $2.9(2.3$ to 3.7$)$ & $0.7(0.4$ to 1.1$)$ \\
\hline
\end{tabular}

The HR of underweight for all CHD subjects relative to the general population was 2.0 (95\% CI 1.8 to 2.3$)$. The risk of underweight was most pronounced for $\mathrm{CHD}$ subjects with severe lesions, univentricular heart (UVH) and those born preterm and with ECD (table 2). Overall, the HR of obesity was 0.8 (95\% CI 0.7 to 1.0 ) for all CHD subjects compared with their age-matched and sex-matched general population controls. There was not a substantial variation of the HRs for obesity according to sex, severity of CHD or presence of prematurity or ECDs (table 2). Results did not change substantially when repeating the analyses with the outlier subject values included. Specifically, the overall prevalence of obesity at first recording in these analyses was $4.9 \%$ (95\% CI 4.7 to 5.2 ) in general population subjects and $4.3 \%$ (95\% CI 3.5 to 5.1 ) in the overall CHD population.

\section{DISCUSSION}

In this study, we evaluated the weight status of children with CHD compared with a large, population-based control group, using data on weight and height collected at preventive health checks offered to all Danish children. Underweight was more prevalent in the CHD population than in the general population. This was most pronounced for individuals with severe CHD including those with UVH but was also observed for individuals with mild CHD. However, among those who were underweight at 1 year of age, with later BMI recordings between ages 2 and 5 years, the prevalence of underweight decreased substantially, suggesting that early underweight status may be largely temporary in both CHD subjects and population controls. The prevalence of obesity among children with CHD was not increased compared with the general population or compared with international normative data. This was true for all the defined categories of CHD severity and in the presence of preterm birth or ECDs.
Our data are in line with and extend the reports on BMI data identified in hospital settings. Studies from USA, Canada and Turkey have reported prevalence estimates of obesity in patients with CHD that were similar to that of controls referred to hospital clinics or compared with normative national data. ${ }^{9-1115}$ A Taiwanese study from 2012 including data from a school survey, performed both in first grade and senior year of high school, also reported a similar prevalence of obesity among individuals with CHD and control subjects. ${ }^{16}$ Underweight, as defined in their study as BMI $<15$ th percentile, was more prevalent in the subjects with $\mathrm{CHD}$, which is consistent with our finding, although the definition of underweight is different. We observed an increased risk of being underweight across all types of CHD. Similarly, a US study from 2013 reported an increased prevalence of failure to thrive in CHD individuals with biventricular heart disease without the need for repair. ${ }^{4}$ As the authors suggested this may partly be attributed to individuals with VSD, which may be haemodynamically significant early in life even if they later self-resolve. Similar mechanisms may potentially pertain to underweight.

With the worldwide increase in obesity, there is still a need for cardiologists and practitioners to address the subject, even though the prevalence of obesity in children with CHD did not differ from the control groups. The fact that obesity rates in the CHD population do not exceed those of the general population does not mean that obesity should be ignored as a risk factor. Obesity remains evident in the CHD community, simply at rates comparable to the general population. In fact, the risk of obesity in those with CHD may be of greater consequence since obesity increases the risk of complications like diabetes mellitus, coronary artery disease and heart failure. ${ }^{26} 27$ Of note, since the relationship between BMI and cardiometabolic risks is complex, and considering that there are inherent limitations of BMI measurements, such as the inability to differentiate between body fat and lean mass, caution should be applied when interpreting our results.

\section{Study strengths and limitations}

Prospective information on height, weight and BMI was obtained via annual preventive health checks offered to all Danish children. As data were only available on $30 \%$ of the population, this does raise the concern for selection bias. However, when we compared our study subjects with the larger available cohorts for both the CHD and the general population groups, the characteristics of the group did not substantially vary according to availability of BMI data. Since these measures were only recently made compulsory, it seems unlikely on review of our data that those subjects with missing BMI data were missing for reasons that predisposed them to abnormal BMI.

The group of subjects with CHD was identified through DNPR, and our results depend on the validity of these diagnoses. The positive predictive value of overall presence of CHD according to the DNRP is reported to be $89 \% .^{28}$ Using the previously described exclusion criteria, the positive predictive value will likely be even higher. ${ }^{19}$ Despite 
a relatively large study population overall, the precision of CHD severity-specific estimates, especially for more complex conditions, was low, leaving variation in HRs statistically insignificant. In addition, a larger study population would have allowed more clinically relevant analyses on subgroups with various types of ECDs.

We defined underweight as less than the fifth percentile and obesity as greater than the 95th percentile relative to BMI levels of children from the general population of the same age and sex. This enabled a comparison that was free from bias due to variation in BMI levels across countries. To further quantify the obesity prevalence in Danish children, we also presented the prevalence of obesity according to an international age-specific and sex-specific BMI standard. ${ }^{22}$ This indicated a relatively low prevalence of obesity in Danish children. However, this does not prevent generalisation of the comparisons of abnormal BMI prevalence estimates of children with and without CHD.

\section{CONCLUSION}

The CHD population had an increased prevalence of underweight, compared with the general population, and this was consistent across all ages from 1 to 15 years of age, as well as various complexities of CHD. Data indicated potential for BMI normalisation among those underweight at age 1 year in both the CHD and general population. We found no evidence to suggest an increased prevalence of obesity in children with CHD compared with the general population.

Contributors SS contributed to the conception of the study design, drafted and revised the manuscript and approved the final manuscript as submitted. M0 contributed to the conception of the study design and data analysis, revised the manuscript and approved the final manuscript as submitted. JGW contributed to the conception of the study design, revised the manuscript and approved the final manuscript as submitted. NM contributed to the conception of the study design, revised the manuscript and approved the final manuscript as submitted.

Funding This work was supported by the Department of Clinical Epidemiology at AarhusUniversity Hospital and the Heart Institute at Cincinnati Children's Hospital.

Competing interests None declared.

Provenance and peer review Not commissioned; externally peer reviewed.

Open Access This is an Open Access article distributed in accordance with the Creative Commons Attribution Non Commercial (CC BY-NC 4.0) license, which permits others to distribute, remix, adapt, build upon this work non-commercially, and license their derivative works on different terms, provided the original work is properly cited and the use is non-commercial. See: http://creativecommons.org/ licenses/by-nc/4.0/

(c) Article author(s) (or their employer(s) unless otherwise stated in the text of the article) 2017. All rights reserved. No commercial use is permitted unless otherwise expressly granted.

\section{REFERENCES}

1. Jousilahti P, Tuomilehto J, Vartiainen E, et al. Body weight, cardiovascular risk factors, and coronary mortality. 15-year followup of middle-aged men and women in eastern Finland. Circulation 1996;93:1372-9.

2. Varan B, Tokel K, Yilmaz G. Malnutrition and growth failure in cyanotic and acyanotic congenital heart disease with and without pulmonary hypertension. Arch Dis Child 1999;81:49-52.
3. Flegal KM, Kit BK, Orpana $\mathrm{H}$, et al. Association of all-cause mortality with overweight and obesity using standard body mass index categories: a systematic review and meta-analysis. JAMA 2013;309:71-82.

4. Daymont C, Neal A, Prosnitz A, et al. Growth in children with congenital heart disease. Pediatrics 2013;131:e236-e242.

5. Soliman AT, Madkour A, Galil MA, et al. Growth parameters and endocrine function in relation to echocardiographic parameters in children with ventricular septal defect without heart failure. $J$ Trop Pediatr 2001;47:146-52.

6. Polat S, Okuyaz C, Hallioğlu O, et al. Evaluation of growth and neurodevelopment in children with congenital heart disease. Pediatr Int 2011;53:345-9.

7. Ogden CL, Carroll MD, Lawman HG, et al. Trends in obesity prevalence among children and adolescents in the United States, 1988-1994 through 2013-2014. JAMA 2016;315:2292-9.

8. Laas E, Lelong N, Thieulin AC, et al. Preterm birth and congenital heart defects: a population-based study. Pediatrics 2012;130:e82 9-e837.

9. Welisch E, Rauch R, Seabrook JA, et al. Are the children and adolescents with congenital heart disease living in Southwestern Ontario really overweight and obese? Cardiol Young 2014;24:848-53.

10. Babaoğlu K, Deveci M, Kayabey Ö, et al. Prevalence of overweight and obesity among patients with congenital and acquired heart disease in Kocaeli, Turkey. Cardiol Young 2015;25:533-8.

11. Shustak RJ, McGuire SB, October TW, et al. Prevalence of obesity among patients with congenital and acquired heart disease. Pediatr Cardiol 2012;33:8-14.

12. Tamayo C, Manlhiot C, Patterson $\mathrm{K}$, et al. Longitudinal evaluation of the prevalence of overweight/obesity in children with congenital heart disease. Can J Cardiol 2015;31:117-23.

13. Pasquali SK, Marino BS, Pudusseri A, et al. Risk factors and comorbidities associated with obesity in children and adolescents after the arterial switch operation and Ross procedure. Am Heart $J$ 2009;158:473-9.

14. Chung ST, Hong B, Patterson L, et al. High Overweight and Obesity in Fontan Patients: A 20-Year History. Pediatr Cardiol 2016;37:192-200.

15. Pinto NM, Marino BS, Wernovsky G, et al. Obesity is a common comorbidity in children with congenital and acquired heart disease. Pediatrics 2007;120:e1157-e1164.

16. Chen CA, Wang JK, Lue HC, et al. A shift from underweight to overweight and obesity in Asian children and adolescents with congenital heart disease. Paediatr Perinat Epidemiol 2012;26:336-43.

17. Epidemiology FL. When an entire country is a cohort. Science 2000;287:2398-9.

18. Schmidt M, Pedersen L, Sørensen HT. The danish civil registration system as a tool in epidemiology. Eur J Epidemiol 2014;29:541-9.

19. Olsen M, Garne E, Sværke C, et al. Cancer risk among patients with congenital heart defects: a nationwide follow-up study. Cardiol Young 2014;24:40-6.

20. Madsen NL, Marino BS, Woo JG, et al. Congenital heart disease with and without cyanotic potential and the long-term risk of diabetes mellitus: A Population-Based Follow-up Study. J Am Heart Assoc 2016;5:e003076.

21. The Children's Database. http://www.esundhed.dk/dokumentation/ Registre/Sider/Register.aspx?rp:A_Register=20\&rp:Visning=0\&

22. Vidmar SI, Cole TJ, Pan H. Standardizing anthropometric measures in children and adolescents with functions for egen: Update. Stata Journal 2013;13:366-78.

23. Cole TJ, Bellizzi MC, Flegal KM, et al. Establishing a standard definition for child overweight and obesity worldwide: international survey. BMJ 2000;320:1240-3.

24. Knudsen LB, Olsen J. The danish medical birth registry. Dan Med Bull 1998;45:320-3.

25. European Surveillance of Congenital Anomalies. Guide 1.3 Instructions for the Registration and Surveillance of Congenital Anomalies 2009 http://www.eurocat-network.eu/content/EUROCATGuide-1.3.pdf (accessed Jan 2014).

26. Wijeysundera HC, Machado M, Farahati F, et al. Association of temporal trends in risk factors and treatment uptake with coronary heart disease mortality, 1994-2005. JAMA 2010;303:1841-7.

27. Eckel RH. Obesity and heart disease: a statement for healthcare professionals from the Nutrition Committee, American Heart Association. Circulation 1997;96:3248-50.

28. Jepsen B, Jepsen P, Johnsen SP, et al. Validity of diagnoses of cardiac malformations in a Danish population-based hospitaldischarge registry. Inter J Risk and Safety in Med 2006;18:77-81. 